\title{
Skeletal Muscle Resting Membrane Potential in Potassium Deficiency
}

\author{
Gordon L. Bilbrey, Luis Herbin, Norman W. Carter, and \\ JAMES P. KNOCHEL \\ From the Department of Medicine, The University of Texas Southwestern \\ Medical School, Dallas, Texas 75235 and the Department of Medicine, \\ Veterans Administration Hospital, Dallas, Texas 75216
}

\begin{abstract}
A B S T R A C T The resting transmembrane potential of skeletal muscle $\left(E_{m}\right)$ is thought to be a function of the ratio of intracellular to extracellular potassium concentration $\left(\left[\mathrm{K}_{i}\right] /\left[\mathrm{K}_{0}\right]\right)$. In potassium deficiency, the fall of $\left[K_{i}\right]$ is proportionately less than the fall of $\left[K_{0}\right]$, thus theoretically predicting a rise of $E_{m}$. To examine this theory and to characterize $E_{m}$ in kaliopenic myopathy, muscle composition and $E_{m}$ were measured during moderate $(n=5)$ and severe $(n=11) \mathrm{K}$ deficiency in the dog and compared with measurements in the severely $\mathrm{K}$-deficient rat $(n=10)$. Mean measured $E_{m}$ rose during moderate $\mathrm{K}$ deficiency in four of five dogs $(-85.4$ to $-94.6 \mathrm{mV}$ ) and during severe $\mathrm{K}$ deficiency in the rat $(-89.1$ to $-94.9 \mathrm{mV})$. Both values closely approximated the increase in $E_{m}$ predicted by the Goldman equation. In contrast, during severe $\mathrm{K}$ deficiency in the dog, a significant decline $(P<0.001)$ of mean $E_{m}$ to $-55 \mathrm{mV}$ was observed.

Since skeletal myopathy and paralysis do not occur in the rat as a consequence of $\mathrm{K}$ deficiency, the observation that $E_{m}$ falls as paralysis occurs in the unexercised dog suggests that alteration of muscle membrane function may play a role in kaliopenic myopathy. Such an event could explain the ease with which frank muscle necrosis may be induced by exercise in the $\mathrm{K}$-deficient dog.
\end{abstract}

\section{INTRODUCTION}

Potassium deficiency in man is a common and potentially serious disorder that may be highlighted by disordered

This work was presented in part, 27 January 1973 at the Renal Section of the Southern Society of Clinical Investigation, New Orleans, La.

Dr. Herbin's work was performed as a post-doctoral fellow at The University of Texas Southwestern Medical School. His present address is Buenos Aires Medical School, Buenos Aires, Argentina.

Received for publication 13 February 1973 and in revised form 16 August 1973. function and structural alteration of skeletal muscle. Characteristically, its most common manifestation is simple weakness. However, life-threatening paralysis and occasionally frank rhabdomyolysis may occur (1).

In a recent experimental study reported from this laboratory, dogs with advanced potassium deficiency demonstrated an impairment of potassium release from contracting muscle that was associated with a marked impairment of exercise hyperemia (2). Such exercise was followed by extensive necrosis of skeletal muscle. These findings suggested that failure of $K+$ release from contracting muscle and in turn, ischemia, played a major role in the pathogenesis of necrosis induced by exercise in potassium deficiency.

In contrast to the prominent functional disorders of skeletal muscle observed in man and dogs with potassium deficiency, comparable deficiency in the rat does not typically lead to skeletal muscle dysfunction but rather cardiomyopathy (3). This species difference suggests that kaliopenic myopathy in man and the dog is pathophysiologically similar but fundamentally different from the effect of potassium deficiency in the rat. The precise factor or factors responsible for such a fundamental difference between these species is not known, but one possibility is a different response of membrane function to changes in potassium.

In health the muscle cell membrane may be considered to function principally as a potassium electrode, although with a slight but significant permeability for sodium (4). Thus instead of the Nernst equation,

$$
E_{m}=-\frac{R T}{F} \ln \frac{[\mathrm{K}+]_{i}}{[\mathrm{~K}+]_{o}}
$$

a modification (the Goldman-Hodgkin-Katz equation [5])

$$
E_{m}=-\frac{R T}{F} \ln \frac{[\mathrm{K}+]_{i}+p[\mathrm{Na}+]_{i}}{[\mathrm{~K}+]_{o}+p[\mathrm{Na}+]_{o}}
$$

The Journal of Clinical Investigation Volume 52 December 1973·3011-3018 
is more appropriately used to predict the resting potential based upon potassium and sodium ion gradients across the membrane. ${ }^{1}$ In equation $2, p$ represents the permeability of sodium relative to potassium which ordinarily has a value of 0.01 . Assuming that $[\mathrm{K}+]_{i} /[\mathrm{K}+]_{0}$ is the main determinant of $E_{m}$, with a relatively constant value for $p$, it would be predicted that although both $[\mathrm{K}+]_{\imath}$ and $[\mathrm{K}+]_{\text {。 }}$ are reduced in $\mathrm{K}+$ deficiency their ratio is increased due to the disproportionate fall of [K +$]_{0}$ and the $E_{m}$ becomes increasingly more negative. Previous studies in rats made $\mathrm{K}+$ deficient have yielded conflicting results; skeletal muscle $E_{m}$ has been either elevated (6) as predicted from the Goldman-HodgkinKatz equation, or has been observed to be reduced $(7,8)$. In a clinical study in man, $E_{m}$ were high in $\mathrm{K}+$-deficient patients (9) in whom myopathy was not evident. Previous measurements of $E_{m}$ in $\mathrm{K}+$-deficient dogs have not been reported.

Severe muscle injury can be induced in dogs as a result of $\mathrm{K}+$ deficiency. Since rats do not develop such lesions, the present study was undertaken to examine the resting skeletal muscle transmembrane potential difference in $\mathrm{K}+$-depleted dogs and rats. The results suggest that $E_{m}$ is predictable by equation 2 in rats even with severe $\mathrm{K}+$ depletion. However, although the $E_{m}$ in dogs rises as predicted in early $\mathrm{K}+$ deficiency, it falls appreciably when the $\mathrm{K}+$ depletion becames severe.

\section{METHODS}

Rat experiments. Together with an appropriate control group, 10 male Sprague-Dawley rats were made severely potassium deficient utilizing an electrolyte-deficient diet previously described (10). Each rat undergoing depletion received $1 \mathrm{mM}$ of sodium sulfate and was given $5 \mathrm{mg}$ of Doca (deoxycorticosterone acetate) into the front leg muscle daily. Control animals received similar amounts of electrolyte-deficient diet to which had been added 1 meq of potassium chloride and $2 \mathrm{meq}$ of sodium choride. At the end of 10 days, both groups of rats were anesthetized with sodium pentobarbital and muscle $E_{m}$ was measured by methods described previously (11). After the measurement of muscle $E_{m}$, aortic blood was taken for measurement of serum electrolyte concentration, and a generous portion of anterior thigh muscle was sampled for analysis of water, sodium, potassium, and chloride. Muscle fat content was determined by petroleum ether extraction. Partition of intra- and extracellular fluid in the muscle samples was derived from the intracellular chloride concentration of each sample based upon the $E_{m}$ measured for each respective rat (12).

Dog expcriments. 11 male mongrel dogs weighing between 16 and $24 \mathrm{~kg}$ were studied, each animal serving as its own control. After a period in which the dogs were allowed to become accustomed to the animal facility en-

${ }^{1}$ In equations 1 and $2, E_{m}=$ transmembrane potential; ion concentrations are used assuming that activity coefficients for the ions are equal inside and out; $-R T / F$ (2.302) for univalent ions has its usual significance and at $37^{\circ} \mathrm{C}$ has a value of $-61.5 \mathrm{mV}$. vironment, control data were obtained as outlined below. Potassium deficiency was induced by daily gavage feeding a K-deficient but otherwise adequate diet as previously described (2) and each dog received $5 \mathrm{mg}$ of Doca intramuscularly during the first 5 days. The severity of potassium depletion was estimated serially by measuring the daily excretion of potassium in the urine (2).

In each dog plasma electrolyte concentration, muscle electrolyte content and skeletal muscle $E_{m}$ were measured before potassium depletion was induced. Studies obtained in $\operatorname{dog} s$ that had sustained a potassium deficit estimated from urine excretion to range between $10-14 \%$ are hereafter referred to as those conducted in early potassium deficiency. Finally, studies were repeated in these and six additional dogs when they were considered to be markedly potassium depleted. At this time, estimated $K$ deficits ranged $20-25 \%$ and each dog manifested apathy, marked muscle weakness, and difficulty in standing. Plasma sodium, potassium, and chloride concentrations were determined by methods previously described (2).

Skeletal muscle transmembrane potential was estimated in the sartorius muscle of each dog. During the estimation of $E_{m}$, the dogs were anesthetized with sodium pentobarbital $20 \mathrm{mg} / \mathrm{kg}$, intubated, and placed on a Harvard respirator (Harvard Apparatus Co., Inc., Millis, Mass.) to maintain $\mathrm{PCO}_{2}$ at a constant level. $E_{m}$ was measured in each $\operatorname{dog}$ by a method utilizing standard Ling electrodes inserted into the muscle through a metallic 18 gauge needle after a percutaneous puncture. This is the same method used to measure muscle $E_{m}$ as that previously reported from this laboratory using the anterior tibial muscles of humans by making use of the Beranic technique (12). The Ling type of electrodes were filled with $\mathrm{KCl}-\mathrm{KNO}_{3}$ solution (3-2.5 $\mathrm{M}$ respective concentrations). Electrodes were selected for low tip potential (less than $10 \mathrm{mV}$ ), and only those having a tip resistance between 5-40 M $\Omega$ were used. Partition of muscle intra- and extracellular fluid volumes was derived by the same method described previously for rat muscle.

Procurement and analysis of dog muscle samples. In each experiment duplicate samples of skeletal muscle (range 10-20 mg wet weight) were obtained with a Baylor biopsy needle (Popper \& Sons, Inc., New York). The precise time at which the muscle sample was obtained was noted, and serial weights at precise intervals were determined using a Cahn electrobalance (Cahn Div., Ventron Instruments Corp., Paramount, Calif.). Samples were transferred to chemically clean Pyrex glass tubes and dried overnight in a vacuum oven at $73^{\circ} \mathrm{C}$. After drying, weight was recorded, muscle fat was extracted with petroleum ether, and samples were then placed in sterile plastic tissue culture tubes ${ }^{2}$ containing $5 \mathrm{ml}$ of $10 \%$ acetic acid solution and lithium nitrate in a concentration of $15 \mathrm{meq} / \mathrm{liter}$. The lithium nitrate provided an appropriate amount of lithium for an internal flame photometric standard. The plastic tubes containing the muscle samples were placed in a Dubnoff metabolic shaker for $24 \mathrm{~h}$ at $37^{\circ} \mathrm{C}$, and thereafter the supernate was analyzed for sodium and potassium concentration using an IL model 143 flame photometer (Instrumentation Laboratory, Inc., Lexington, Mass.). The

${ }^{2}$ We consider the use of plastic tubes a critically important modification in electrolyte extraction of small muscle samples. In preliminary experiments, digestion of small muscle samples in glassware elevated sodium concentration in the supernate as much as $30 \%$ regardless of the type of glassware or cleaning procedure used. 
flame photometer was adjusted to zero with acetic acidlithium solution and standardized with a solution containing acetic acid (10\%), lithium nitrate (15 meq/liter), $\mathrm{NaCl}$ (0.1 meq/liter) and $\mathrm{KCl}(0.4 \mathrm{meq} / \mathrm{liter})$, with $\mathrm{Na}$ and $\mathrm{K}$ readings set at 20 and 80 , respectively. To obtain the true concentration, standard and sample readings were divided by 200. The standard curve for sodium concentration was linear between 0.025 and $0.150 \mathrm{meq} / \mathrm{liter}$; for potassium between 0.1 and $0.6 \mathrm{meq} / \mathrm{liter}$.

$2 \mathrm{ml}$ of supernate was used for duplicate chloride analysis by the method of Nichols, Hazelwood, and Barnes (13) using a $680 \mathrm{M} \Omega$ external resistor on the Cotlove chloridometer.

To validate the method for electrolyte analysis on small samples of skeletal muscle obtained by needle biopsy, a normal dog was anesthetized, and six microbiopsies were obtained from the gracilis muscle as well as six macrosamples. The macrosamples were approximately 80-90 times heavier than the microsamples obtained by the needle technique. The methods used to determine water and electrolyte content of the macrosamples were the same as those previously described in this laboratory for human muscle biopsies (12). $E_{m}$ was utilized to calculate intracellular chloride concentration and to partition intra- and extracellular fluid.

\section{RESULTS}

Validation of the micromuscle biopsy procedure. Table $\mathrm{I}^{\mathbf{3}}$ compares the data obtained for muscle analysis utilizing the standard macromethod and the micromethod for the dog experiments. The wet weight of the macrosamples varied between 0.941 and $1.645 \mathrm{~g}$. The microsamples weighed between 11.9 and $18.2 \mathrm{mg}$ wet weight. As can be seen from Table I, estimation of water content yielded higher values in the microsamples than in the macrosamples. By this method the sodium and chloride values expressed per $100 \mathrm{~g}$ fat-free dry weight (FFDW) were somewhat higher in microsamples than in macrosamples. However, when the calculated intracellular concentrations of sodium and potassium were compared, there was no significant difference between the two results. It would appear that microsamples contain more extracellular fluid presumably due to mechanical trauma incident to the method of biopsy. Nevertheless, when correction is made for water partition by estimating intracellular chloride concentration (4.2 meq/ liter), which in turn is dependent upon $E_{m}(90 \mathrm{mV})$ of the muscle (12), the intracellular sodium and potassium concentrations estimated by both methods were not significantly different.

Potassium dcpletion in the rat. In Table II, mean values for potassium-deficient rats are compared with

${ }^{3}$ Abbrcviations used in this paper: $\mathrm{Na}+{ }_{m}, \mathrm{Cl}_{m}^{-}$, and $\mathrm{K}+_{m}$, milliequivalents of sodium, chloride, and potassium/ $100 \mathrm{~g}$ fat-free dry weight of muscle; TW, ECW, and ICW, total, extra-, and intracellular water expressed as $\mathrm{ml} / 100 \mathrm{~g}$ fat-free dry weight of muscle; $[\mathrm{Na}+]_{i},\left[\mathrm{Cl}^{-}\right]_{i}$, and $[\mathrm{K}+]_{d}$, milliequivalents of ion/liter of muscle intracellular water; measured and predicted (Goldman) resting membrane potential $\left(E_{m}\right)$ are expressed in millivolts. values for control animals. Serum potassium fell significantly from a mean control value of $4.3 \pm 0.5-1.5 \pm 0.2$ meq/liter $(P<0.001)$ and was accompanied by a hypochloremic metabolic alkalosis with a mean blood $\mathrm{pH}$ of 7.54 (Table IV). Intracellular potassium concentration in rats was $97.0 \pm 11.0$ and associated with the anticipated rise in intracellular sodium. Although muscle chloride content fell slightly, the difference was not significantly different from the control value (Table II). On the other hand, intracellular chloride concentration in the potassium-deficient rats was calculated to be $2.8 \pm 0.3$ as opposed to $4.2 \pm 0.2$ in the control group $(P<0.001)$. Nevertheless, the calculated intracellular water space for muscle was not significantly different between the two groups of rats (Table II).

Resting transmembrane potential in the rat. The resting $E_{m}$ in the control group of rats was $-89.1 \pm 1.1 \mathrm{mV}$. This value compared very favorably with that previously published from this laboratory (11). The Goldman equation predicts the mean $E_{m}$ for the control group of rats to be $-88.6 \pm 2.5 \mathrm{mV}$. The $E_{m}$ found for, all of the potassium-deficient rats with two exceptions was at or above the Goldman predicted value for $E_{m}$. The measured $E_{m}$ was $-94.9 \pm 2.9 \mathrm{mV}$, and the predicted value was $-92.1 \pm 2.6 \mathrm{mV}$. Therefore, severe potassium deficiency in the rat is accompanied by an appropriately elevated $E_{m}$ as would be predicted by the Goldman equation. This is illustrated in Fig. 1 in which the measured $E_{m}$ for each individual rat is plotted against the log

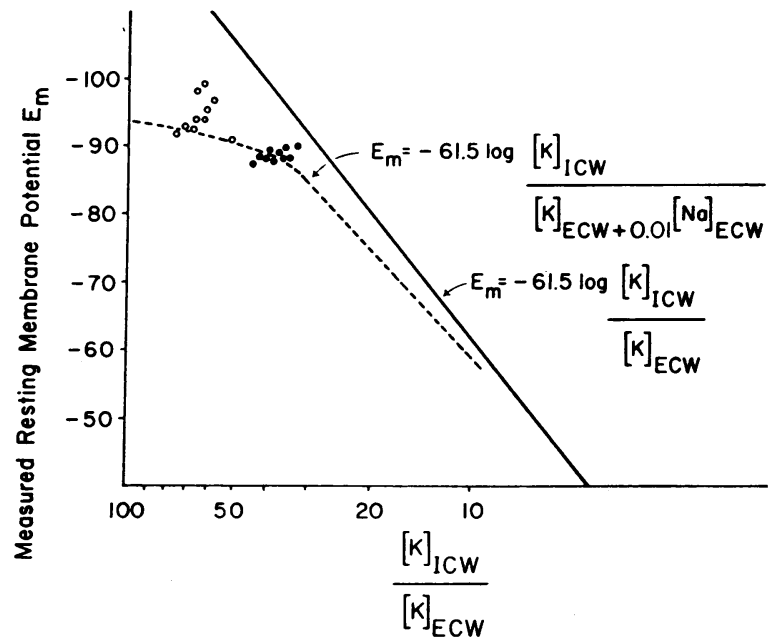

FIGURE 110 control rats were studied (closed circles) with an equal number of severely K-deficient rats (open circles). The terminal portion of the Goldman line is slightly different than the dog and is related to extracellular sodium concentration in the $\mathrm{K}$-deficient state. Values for $E_{m}$ are in millivolts. $[\mathrm{K}]_{\mathrm{row}}$ and $[\mathrm{K}]_{\mathrm{ECw}}$ represent $\mathrm{K}$ ion concentration in milliequivalents per liter of intra- and extracellular water respectively. 
TABLE I

Dog Muscle Analysis*

\begin{tabular}{|c|c|c|c|c|c|c|c|c|c|}
\hline Sample & $\mathrm{H}_{2} \mathrm{O}$ & TW & ECW & ICW & $\mathrm{Na}_{m}$ & $\mathrm{Cl}_{m}$ & $\mathrm{~K}_{m}$ & $\mathrm{Na} i$ & $\mathbf{K}_{\boldsymbol{i}}$ \\
\hline & $\%$ & \multicolumn{3}{|c|}{$m l / 100 \mathrm{~g} F F D W$} & \multicolumn{3}{|c|}{$m e q / 100 \mathrm{~g} F F D W$} & \multicolumn{2}{|c|}{ meq/liter $I C W$} \\
\hline \multicolumn{10}{|c|}{ Marcomethod } \\
\hline 1 & 75.5 & 313 & 62 & 251 & 12.1 & 8.8 & 39.2 & 11 & 156 \\
\hline 2 & 76.6 & 331 & 69 & 262 & 16.0 & 9.6 & 36.9 & 21 & 141 \\
\hline 3 & 75.2 & 308 & 50 & 258 & 10.0 & 7.2 & 35.1 & 10 & 136 \\
\hline 4 & 75.0 & 307 & 42 & 265 & 10.6 & 6.2 & 35.5 & 16 & 134 \\
\hline 5 & 74.0 & 293 & 64 & 229 & 13.6 & 9.0 & 30.1 & 18 & 131 \\
\hline 6 & 74.9 & 302 & 42 & 260 & 10.0 & 6.3 & 33.8 & 14 & 130 \\
\hline$\overline{\mathrm{X}}$ & 75.2 & 309 & 55 & 254 & 12.0 & 7.8 & 35.1 & 15.0 & 138.0 \\
\hline SD & 0.8 & 12 & 12 & 13 & 2.4 & 1.5 & 3.1 & 4.2 & 9.6 \\
\hline \multicolumn{10}{|c|}{ Micromethod } \\
\hline 1 & 76.8 & 281 & 77 & 204 & 13.4 & 10.6 & 31.2 & 8.8 & 153 \\
\hline 2 & 75.8 & 322 & 72 & 250 & 15.2 & 10.0 & 36.4 & 17.6 & 146 \\
\hline 3 & 76.9 & 345 & 63 & 282 & 13.6 & 8.9 & 38.7 & 14.9 & 137 \\
\hline 4 & 77.3 & 381 & 130 & 251 & 21.6 & 17.2 & 28.7 & 8.4 & 114 \\
\hline 5 & 77.6 & 360 & 72 & 288 & 13.1 & 10.0 & 39.0 & 8.0 & 135 \\
\hline 6 & 77.3 & 346 & 94 & 252 & 18.4 & 12.7 & 33.5 & 17.1 & 133 \\
\hline$\overline{\mathbf{X}}$ & 77.0 & 339 & 85 & 254 & 15.9 & 11.6 & 34.6 & 12.5 & 136.3 \\
\hline SD & 0.6 & 34 & 24 & 30 & 3.4 & 3.0 & 4.2 & 4.6 & 13.3 \\
\hline
\end{tabular}

* See footnote 3 for definition of abbreviations.

$[\mathrm{K}+]_{r} /[\mathrm{K}+]_{0}$. The $E_{m}$ values for the control animals represented by the solid dots fall closely to the dotted line generated by the Goldman equation. As opposed to the dog in late potassium deficiency, each $E_{m}$ for individual rats falls on or above the dotted line.

Potassium depletion in the dog. Each dog served as his own control, and five of the dogs were studied in both early and late potassium deficiency. Mean values are shown for muscle and serum composition of 11 dogs in Table III. In five dogs studied during early potas- sium deficiency, there was a significant decrease in serum potassium concentration $(P<0.001)$ as well as muscle potassium content, $(P<0.01)$ by paired " $t$ " analysis. Intracellular potassium concentration was also decreased $(P<0.01)$. Mean values for muscle water, sodium, and chloride content were not significantly different from control values.

Serum potassium was severely depressed during late potassium deficiency $(1.6 \pm 0.3 \mathrm{meq} / \mathrm{liter})$ and accompanied by a metabolic acidosis (Table IV). There was

TABLE II

Muscle Composition and $E_{m}$ in the Rat*

\begin{tabular}{|c|c|c|c|c|c|c|c|c|c|c|c|c|c|}
\hline Rat & $\mathrm{H}_{2} \mathrm{O}$ & $\mathrm{Na}+m$ & $\mathrm{Cl}^{-}{ }_{m}$ & $\mathrm{~K}+m$ & TW & ECW & ICW & {$[\mathrm{Na}+$} & {$\left[\mathrm{Cl}^{-}\right]_{i}$} & {$[\mathrm{~K}+]_{i}$} & $\begin{array}{l}{[\mathrm{K}+]_{\mathrm{ECW} /} /} \\
{[\mathrm{Na}+]_{\mathrm{ECW}}}\end{array}$ & $\begin{array}{c}\text { Gold- } \\
\text { man } \ddagger \\
E_{m}\end{array}$ & $\begin{array}{c}\text { Mea- } \\
\text { sured } \\
E_{m}\end{array}$ \\
\hline & $\%$ & \multicolumn{3}{|c|}{$m e q / 100 \mathrm{~g} F F D W$} & \multicolumn{3}{|c|}{$m l / 100 \mathrm{~g} \mathrm{FFDW}$} & \multicolumn{2}{|c|}{ meq/liter ICW } & & & $-m V$ & $-m V$ \\
\hline \multicolumn{14}{|c|}{ Controls $(n=10)$} \\
\hline Mean & 76.1 & 8.3 & 5.2 & 47.4 & 330.0 & 35.0 & 297.0 & 10.5 & 4.2 & 159.0 & $4.3 / 148.0$ & 88.6 & 89.1 \\
\hline SD & 0.1 & 0.8 & 0.8 & 1.6 & 5.0 & 6.0 & 4.0 & 1.6 & 0.2 & 4.0 & $0.5 / 4$ & 2.5 & 1.1 \\
\hline \multicolumn{14}{|c|}{$\mathrm{K}$ deficient $(n=10)$} \\
\hline Mean & 75.5 & 21.9 & 4.2 & 28.1 & 323.0 & 33.0 & 290.0 & 58.0 & 2.8 & 97.0 & $1.5 / 151.0$ & 92.1 & 94.9 \\
\hline SD & 0.5 & 3.5 & 0.4 & 2.7 & 10.0 & 5.0 & 7.0 & 7.0 & 0.3 & 11.0 & $0.2 / 3.0$ & 2.6 & 2.9 \\
\hline
\end{tabular}

Data on individual animals can be obtained from the ASIS National Auxiliary Publications Service ([NAPS document no. 02189], ASIS/ NAPS, Microfiche Publications, New York 10017).

* See footnote 3 for definition of abbreviations.

$\ddagger$ Goldman $E_{m}$ is $E_{m}$ calculated using determined electrolyte concentrations in equation 2 of text. 
TABLE III

Muscle Composition and $E_{m}$ in the Dog*

\begin{tabular}{|c|c|c|c|c|c|c|c|c|c|c|c|c|c|}
\hline Dog & $\mathrm{H}_{2} \mathrm{O}$ & $\mathrm{Na}+m$ & $\mathrm{Cl}^{-}{ }_{m}$ & $\mathbf{K}+m$ & TW & ECW & ICW & {$[\mathrm{Na}+]_{i}$} & {$\left[\mathrm{Cl}^{-}\right]_{i}$} & {$[\mathrm{~K}+]_{i}$} & $\begin{array}{l}{[\mathrm{K}+] \mathrm{Ecw} /} \\
{[\mathrm{Na}+] \mathrm{Ecw}}\end{array}$ & $\begin{array}{c}\text { Gold- } \\
\text { man } \\
E_{m}\end{array}$ & $\begin{array}{c}\text { Mea- } \\
\text { sured } \\
E_{m}\end{array}$ \\
\hline & $\%$ & \multicolumn{3}{|c|}{$m e q / 100 \mathrm{~g} \mathrm{FFDW}$} & \multicolumn{3}{|c|}{$m l / 100 \mathrm{~g} \mathrm{FFDW}$} & \multicolumn{3}{|c|}{ meq/liter $I C W$} & & $-m V$ & $-m V$ \\
\hline \multicolumn{14}{|c|}{ Control $(n=11)$} \\
\hline Mean & 75.4 & 12.0 & 9.0 & 37.2 & 329.0 & 67.0 & 262.0 & 8.4 & 4.2 & 142.1 & $4.1 / 147.0$ & 86.6 & 90.1 \\
\hline $\mathrm{SD}$ & 1.2 & 2.2 & 2.1 & 4.1 & 17.0 & 18.0 & 23.0 & 5.0 & 1.1 & 11.2 & $0.5 / 3.3$ & 2.8 & 6.4 \\
\hline \multicolumn{14}{|c|}{ Early $\mathrm{K}$ deficiency $(n=5)$} \\
\hline Mean & 73.8 & 16.0 & 10.6 & 27.1 & 306.0 & 78.0 & 228.0 & 18.7 & 4.3 & 120.2 & $2.4 / 151.0$ & 93.6 & 92.4 \\
\hline SD & 2.2 & 2.3 & 0.8 & 4.0 & 26.0 & 11.0 & 26.0 & 13.3 & 1.0 & 16.5 & $0.4 / 2.3$ & 7.4 & 8.3 \\
\hline \multicolumn{14}{|c|}{ Late $\mathrm{K}$ deficiency $(n=11)$} \\
\hline Mean & 73.4 & 17.5 & 10.1 & 25.4 & 301.0 & 50.0 & 251.0 & 3.3 .5 & 18.0 & 104.2 & $1.6 / 150.0$ & 94.8 & 54.8 \\
\hline SD & 2.3 & 3.2 & 2.3 & 4.0 & 26.0 & 18.0 & 28.0 & 14.8 & 7.1 & 16.8 & $0.3 / 3.1$ & 4.8 & 5.0 \\
\hline
\end{tabular}

Data on individual animals can be obtained from the ASIS National Auxiliary Publications Service (NAPS document no. 02189).

* See footnote 3 for definition of abbreviations.

$\ddagger$ Goldman $E_{m}$ is $E_{m}$ calculated using determined electrolyte concentrations in equation 2 of text.

a small $(2 \%)$ but significant $(P<0.01)$ decrease in total muscle water content (Table III). Intracellular potassium concentration decreased from a mean control level of $142.1 \pm 11.2-104.2 \pm 16.8(P<0.001)$, and intracellular sodium concentration rose from a mean control value of $8.4 \pm 5.0-33.5 \pm 14.8 \mathrm{meq} / \mathrm{liter}$ of intracellular water $(P<0.001)$. Intracellular chloride, calculated from the transmembrane potential and extracellular chloride concentration (12), rose from 4.2 $\pm 1.1-18.0 \pm 7.1$ $\mathrm{meq} /$ liter of intracellular water $(P<0.001)$. Likewise, muscle sodium and potassium content expressed as meq/100 g FFDW showed changes similar in direction and magnitude to those expressed as concentration in intracellular water and were significantly different from control values $(P<0.001)$. There was no significant change in muscle chloride content. Serum chloride concentration in early and late potassium deficiency remained unchanged from control values.

Resting transmembrane potential in the dog. When resting transmembrane potential $\left(E_{m}\right)$ was measured in the dog, the usual stairstep increase in $E_{m}$ was found that has been previously described (12) as the electrode penetrated into deeper muscle fibers. Thus, a plateau was attained that is defined as that point where successive impalement of muscle fibers gave a constant value. Upon reaching the plateau, a minimum of six muscle potentials were recorded in each dog and averaged. Minimal muscle cell heterogeneity was present in that the standard deviation of control $E_{m}$ was \pm 2.9 $\mathrm{mV}$ and did not exceed this value during $\mathrm{K}$ deficiency.

The mean values of $E_{m}$ obtained in the control period, early $\mathrm{K}+$ deficiency and late $\mathrm{K}+$ deficiency are shown in Table III. In each animal the predicted $E_{m}$ was calculated from appropriate data utilizing the Goldman equation (equation 2). This value was compared with the measured $E_{m}$. In 6 of the dogs, control measure- ments of $E_{m}$ were very close to the predicted value. In three dogs the measured $E_{m}$ values were somewhat higher than the predicted values. In one dog an unusually low $E_{m}$ was found $(78 \mathrm{mV})$, and for this reason the control measurements were made and verified on 2 successive days. The value in this dog was nearly $6 \mathrm{mV}$ below that predicted. Nevertheless, the mean control value for predicted $E_{m}(86.6 \pm 2.8 \mathrm{mV})$ closely approximated the mean value for the measured $E_{m}$ $(90.1 \pm 6.4)$ in the control period.

Measured $E_{m}$ during early potassium deficiency (mean serum potassium concentration $2.4 \pm 0.4 \mathrm{meq} /$ liter) rose in four dogs from a mean value of -85.4 $\pm 5.3--94.6 \pm 7.7 \mathrm{mV}$ (Fig. 2). In one of the dogs in the early $K$ deficiency period, there was a slight fall in measured $E_{m}$ (Fig. 2). Nevertheless, the mean measured $E_{m}$ of $-92.4 \pm 8.3$ closely approximated the predicted $E_{m}$ of $-93.6 \pm 7.4$ for all of the dogs in the early $\mathrm{K}$ deficiency period (Table III).

TABLE IV

Blood Acid-Base Status of Dog and Rat during $K$ Deficiency

\begin{tabular}{lrrr}
\hline \multirow{2}{*}{$*$} & $\mathrm{pH}$ & $\mathrm{P}_{\mathrm{CO}_{2}}$ & $\mathrm{HCO}_{3}-$ \\
\hline & & $m m \mathrm{Hg}$ & $m e q /$ liter \\
Dog & & & \\
Control & 7.35 & 45.0 & 24.5 \\
& \pm 0.02 & \pm 5.4 & \pm 2.8 \\
Early K deficiency & 7.29 & 42.5 & 19.6 \\
& \pm 0.08 & \pm 8.5 & \pm 3.4 \\
Late K deficiency & 7.29 & 34.9 & 17.0 \\
& \pm 0.11 & \pm 7.8 & \pm 2.0 \\
Rat & & & \\
Control & 7.41 & 38.0 & 24.0 \\
& \pm 0.02 & \pm 2.0 & \pm 1.8 \\
K deficient & 7.54 & 44.0 & 37.0 \\
& \pm 0.03 & \pm 2.4 & \pm 2.2 \\
\hline
\end{tabular}

* Values represent mean and standard deviation. 


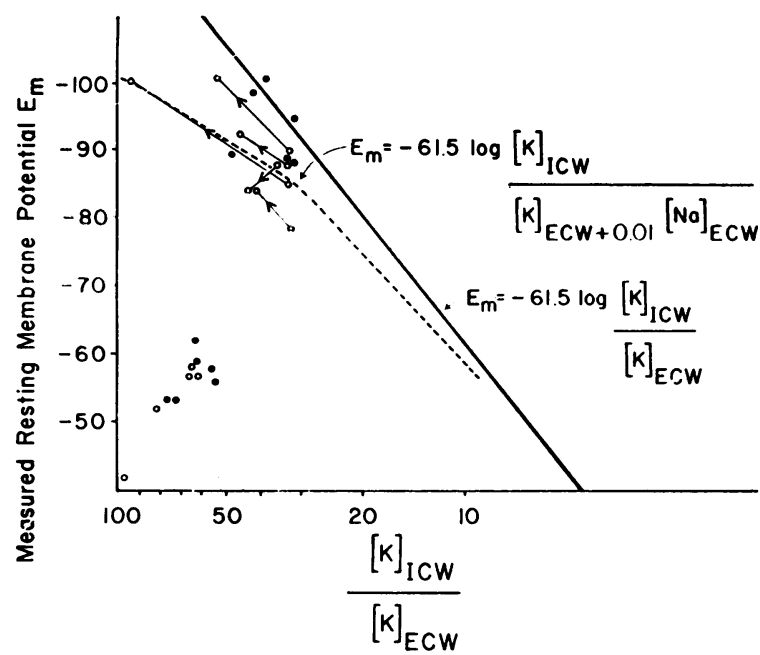

FIGURE 2 Five dogs were studied during control and early potassium-deficient periods (open circles with arrows) and again during late potassium deficiency (open circles). Six dogs were studied during control and late potassiumdeficient periods (solid circles). All late potassium-deficient dogs are represented in the lower left corner. $E_{m},[\mathrm{~K}]_{\mathbf{I C w}}$, and $[\mathrm{K}]_{\mathrm{ECw}}$ are defined as in Fig. 1.

In striking contrast to the agreement between predicted and measured $E_{m}$ in normal or early K-deficient dogs, those with late potassium deficiency depleted of $20 \%$ or more of their normal estimated total body $\mathrm{K}$ content showed a pronounced fall of measured $E_{m}$ (Table III). The disparity between the measured and predicted potentials are illustrated in Fig. 2. It can be seen that in both the control period and the period of early potassium deficiency, the measured $E_{m}$ for each dog is closely predicted by the Goldman equation, whereas measured $E_{m}$ in all dogs with severe $\mathrm{K}+\mathrm{de}$ ficiency were considerably below the predicted $E_{m}$ values.

\section{DISCUSSION}

In a previous report from this laboratory, it was shown that rhabdomyolysis (i.e., muscle necrosis), could be induced by exercise in potassium-deficient dogs (2). Moreover, it was found that the basal serum creatine phosphokinase levels were elevated, suggesting either some degree of muscle necrosis or altered membrane permeability with leakage of enzymes out of cells. The present study provides additional information suggesting that severe potassium deficiency markedly alters skeletal muscle membrane function. During the early phases of potassium depletion, the resting membrane potential $\left(E_{m}\right)$ increased in a direction predicted by the Goldman-Hodgkin-Katz equation. However, as the potassium deficiency became more severe, exceeding $20 \%$ of body stores, the $E_{m}$ fell far below the predicted value indicating a marked alteration of the electrical properties of the membrane. Associated with this more severe degree of potassium deficiency, the dogs became noticeably weak and sometimes demonstrated muscle paralysis. Such findings appear to be closely related to the syndrome of severe potassium depletion in man (1)

In contrast, potassium deficiency in rats, despite more pronounced depression of skeletal muscle potassium content and comparable serum potassium concentration, do not manifest obvious weakness and apparently never demonstrate overt skeletal muscle paralysis. Rather, there has been only one report of any sig nificant pathology in skeletal muscle of potassiumdeficiency rats (14); whereas, from other reports (3) and in our own experience no pathologic lesions in potassium-deficient rat muscle have been observed. In view of the paucity of muscle pathology in potassiumdeficient rats, it is of great interest that in the present studies the skeletal muscle resting transmembrane potential in the potassium-deficient rat is not only maintained but is increased as predicted by equation (2) above.

The observations that muscular paralysis and necrosis are prominent findings in the $\mathrm{K}$-deficient dog but not the rat suggests a fundamental biologic difference between the two species. Although we favor this view, the possibility must also be considered that this apparent species difference is the result of variation in experimental design. Thus, the rats not only received Doca in comparably larger doses than the dogs but also throughout the period of depletion. Although considered to be highly unlikely, we did not examine the possibility that Doca might have sustained a normal $E_{m}$ in the dog if it had been administered throughout the depletion process. Moreover, in previous experiments from this laboratory (15), rats make $\mathrm{K}^{+}$deficient by dietary deprivation for 40 days without Doca had high skeletal transmembrane potentials that were predictable by the Goldman equation using a $\mathrm{pNa}+$ of 0.01 .

Although we contend that $\mathrm{K}$ deficiency induced a defect in muscle membrane integrity in the dog, which in turn induced the fall of $E_{m}$, the possibility should also be considered that the observed changes were related to the duration of $\mathrm{K}$ deficiency. The time required to produce severe potassium deficiency in the rat was 10 days. This is approximately half the time required for inducing such a deficiency in dogs by the methods utilized. Thus, if normal potassium stores are required for either maintenance or synthesis of the muscle membrane, it would seem possible that a

'Muirhead, E. E., D. W. Seldin, and N. W. Carter. 1952. Unpublished observations. 
finite period of time would be required for such changes to occur. It seems possible therefore, that if $\mathrm{K}$ deficiency were maintained for a sufficiently long period of time in the rat, the apparent "species difference" between the rat and the dog could well disappear.

Our observation that muscle $E_{m}$ in rats with advanced potassium deficiency rises to abnormally high values is similar to observations reported by Bolte and Luderitz (6). Two previous reports of low, i.e., less negative $E_{m}$ in $\mathrm{K}+$-deficient rats obviously conflict with the presently reported results $(7,8)$. In the report of Eckel and Sperlakis, it is not clear if $E_{m}$ were reported only after a plateau value for a given rat had been obtained; retention of artifactually low potentials in establishing the mean $E_{m}$ for a given rat would necessarily lead to low values. One of their control groups (group I) (7) had a particularly low value for $E_{m}$ in normal rats $(-80.8 \pm 2.7 \mathrm{mV})$. It should also be noted that in their group II, the mean $E_{m}$ for $\mathrm{K}+$-deficient rats did not differ from control $E_{m}$ of that group (7). In the report of Kendig and Bunker (8), artifactually low surface potentials were apparently not used in calculating the mean $E_{m}$ for a given rat. Nevertheless, in $\mathrm{K}+$-depleted rats in their study, $E_{m}$ not only did not rise but in one group of animals actually fell below control value. There were, however, only three rats in this group. A major and perhaps important difference in the data of Kendig and Bunker was the extremely high values for external $[\mathrm{K}+]$; control values ranged to $7.0 \mathrm{meq} / \mathrm{liter}, \mathrm{K}+-$ deficient values were all over $3.2 \mathrm{meq} / \mathrm{liter}$. It appears that the degree of potassium deficiency induced by both groups of investigators was no greater than that induced in the presently reported study. Our rats were housed in small metabolic cages and were not required to expend much muscular energy as the potassium deficiency developed. In light of the previous study in dogs from this laboratory (2), which showed that frank rhabdomyolysis required not only potassium deficiency but exercise stress, the possibility arises that, in the rat study reporting low skeletal muscle $E_{m}$, there might have been a difference in the degree of muscular activity. It should be stressed however that in the case of the dog, the fall in skeletal muscle $E_{m}$ occurred without any increase in muscular stress over that normally undertaken by a caged animal.

Resting skeletal muscle $E_{m}$ has been reported previously in five human subjects with potassium deficiency (9). In control individuals the mean value for $E_{m}$ was $-87.2 \mathrm{mV}$, which was significantly different than the value of $-101.7 \mathrm{mV}$ found in the five potassium-deficient human subjects. It must be emphasized however that in these subjects, the illnesses causing potassium deficiency were not severe and were of vari- able etiology, and only a moderate degree of potassium deficiency was present (mean serum potassium concentration was $2.6 \mathrm{meq} /$ liter $)$. We would interpret these findings in the humans to be analogous to our dogs at the state of early potassium deficiency. Thus, with modest potassium deficiency the resting muscle $E_{m}$ would be predictably elevated. Since humans can develop muscle paralysis and rhabdomyolysis on the basis of potassium deficiency per se (1), it might be suggested that in severely potassium-deficient humans, the resting muscle membrane potential would be depressed as it has been found in the present study in the late potassium-deficient state in dogs.

The exact alteration in membrane function responsible for the fall of $E_{m}$ in dogs during late potassium deficiency cannot be determined from these studies. It has generally been accepted that sodium is actively extruded from and potassium is pumped into cells by a coupled nonelectrogenic exchange process and that concentration gradients that are generated by this mechanism give rise to diffusion potentials. The resulting transmembrane potential can then be explained by the Goldman-Hodgkin-Katz equation in which the relative permeability of sodium to potassium is approximately 0.01 . Alternatively, as originally suggested by Conway (16), the pump responsible for sodium extrusion from the cell might be electrogenic. In view of these two possibilities, the resting $E_{m}$ in the severely potassium-deficient dogs might fall either as a result of an impairment of an electrogenic sodium pump or alternatively as a loss of selective ion permeability of the muscle membrane. The data in the present study could be explained if the relative permeability coefficient of sodium increased from a level of $0.01-0.08$.

\section{ACKNOWLEDGMENTS}

The technical assistance of James Long, Deloia Morris, Stafford Cassel, John Huff, James Hoback, and Russell Horn is gratefully acknowledged. The secretarial assistance of Mrs. Linda Edwards is also acknowledged.

This work was supported in part by the Veterans Administration, U. S. Public Health Service grant 5 PO1 HE11662, the Hoechst Pharmaceutical Company, The Upjohn Company, and the Dallas Diabetes Association.

\section{REFERENCES}

1. Campion, D. S., J. M. Arias, and N. W. Carter. 1972. Rhabdomyolysis and myoglobinuria association with hypokalemia of renal tubular acidosis. J. Am. Med. Assoc. 220: 967.

2. Knochel, J. P., and E. M. Schlein. 1972. On the mechanism of rhabdomyolysis in potassium depletion. $J$. Clin. Invest. $51: 1750$.

3. Smith, S. G., B. Black-Schaffer, and T. E. Lasater. 1950. Potassium-deficiency syndrome in the rat and the dog. A description of the muscle changes in the potassium-depleted dog. Arch. Pathol. 49: 185.

4. Hodgkin, A. L., and B. Katz. 1949. The effect of sodium 
ions on the electrical activity of the giant axon of the squid. J. Physiol. (Lond.). 108: 37.

5. Goldman, D. E. 1943. Potential impedance and rectification in membranes. J. Gen. Physiol. 27: 37.

6. Bolte, H. D., and B. Lüderitz. 1968. Membranpotentiale bei experimentellem Kakummangel. Messungen am Rattenzwerchfell in vitro. Pflueger Arch. Gesamte Physiol. Menschen Tiere. 301 : 43.

7. Eckel, R. E., and N. Sperlakis. 1963. Membrane potentials in K-deficient muscle. Am. J. Physiol. 205: 307.

8. Kendig, J. J., and J. P. Bunker. 1970. Extracellular space, electrolyte distribution and resting potential in K depletion. Am. J. Physiol. 218: 1737.

9. Riecker, G., H. D. Bolte, and D. Röhl. 1964. Hypokaliämie und Membranpotential. Mikropunktionen eizelner Muskelzellen Beim Menschen. Reanimation Organes Artificiels. 1 : 41.

10. Carter, N. W., D. W. Seldin, and H. C. Teng. 1959. Tissue and renal response to chronic respiratory acidosis. J. Clin. Invest. 38 : 949.

11. Carter, N. W., F. C. Rector, Jr., D. S. Campion, and
D. W. Seldin. 1967. Measurement of intracellular $\mathrm{pH}$ of skeletal muscle with $\mathrm{pH}$-sensitive glass microelectrodes. J. Clin. Invest. 46: 920.

12. Cunningham, J. N., Jr., N. W. Carter, F. C. Rector, Jr., and D. W. Seldin. 1971. Resting transmembrane potential difference of skeletal muscle in normal subjects and severely ill patients. J. Clin. Invest. 50: 49.

13. Nichols, B. L., C. F. Hazelwood, and D. J. Barnes. 1968. Percutaneous needle biopsy of quadriceps muscle. Potassium analysis in normal children. J. Pediatr. 72 : 840.

14. Cohen, J., R. Schwartz, and W. M. Wallace. 1952 Lesions of epiphyseal cartilage and skeletal muscle in rats on a diet deficient in potassium. Arch. Pathol. 54: 119.

15. Campion, D. S., N. W. Carter, F. C. Rector, Jr., and D. W. Seldin. 1968. Intracellular $\mathrm{pH}\left(\mathrm{pH}_{1}\right)$ in chronic potassium deficiency in the rat. Clin. Res. 16: 379.

16. Conway, E. J. 1957. Nature and significance of concentration relations of potassium and sodium ions in skeletal muscle. Physiol. Rev. 37: 84. 